\title{
Calcium signaling in immune cells
}

\author{
Monika Vig and Jean-Pierre Kinet \\ Laboratory of Allergy and Immunology, Department of Pathology, Beth Israel Deaconess Medical \\ Center and Harvard Medical School, Boston, Massachusetts 02115, USA
}

\section{Abstract}

Calcium acts as a second messenger in many cell types, including lymphocytes. Resting lymphocytes maintain a low concentration of $\mathrm{Ca}^{2+}$. However, engagement of antigen receptors induces calcium influx from the extracellular space by several routes. A chief mechanism of $\mathrm{Ca}^{2+}$ entry in lymphocytes is through store-operated calcium (SOC) channels. The identification of two important molecular components of SOC channels, CRACM1 (the pore-forming subunit) and STIM1 (the sensor of stored calcium), has allowed genetic and molecular manipulation of the SOC entry pathway. In this review, we highlight advances in the understanding of $\mathrm{Ca}^{2+}$ signaling in lymphocytes with special emphasis on SOC entry. We also discuss outstanding questions and probable future directions of the field.

In lymphocytes, crosslinking of antigen receptors typically activates phosphoinositide-specific phospholipase $\mathrm{C}$. Phospholipase $\mathrm{C}$ breaks down phosphatidylinositol-4,5-bisphosphate to generate inositol-1,4,5-trisphosphate $\left(\operatorname{Ins}(1,4,5) \mathrm{P}_{3}\right)$ and diacylglycerol. $\operatorname{Ins}(1,4,5) \mathrm{P}_{3}$ binds its receptor located on the surface of internal $\mathrm{Ca}^{2+}$ stores, mainly the endoplasmic reticulum, and activates the release of $\mathrm{Ca}^{2+}$ into the cytoplasm. This event, known as 'store depletion', in turn activates store-operated calcium (SOC) channels in the plasma membrane to recruit $\mathrm{Ca}^{2+}$. Lymphocytes are believed to use SOC entry (SOCE) as the main mode of $\mathrm{Ca}^{2+}$ influx. The best characterized SOC channels in lymphocytes are known as 'calcium release-activated calcium' (CRAC) channels ${ }^{1}$. CRAC channels are highly $\mathrm{Ca}^{2+}$-selective, low-conductance channels with a characteristic inwardly rectifying current-voltage relationship. The past few years have brought substantial progress in understanding the molecular composition of the CRAC signaling complex. High-throughput screens based on RNA-mediated interference have identified STIM1 (stromal interaction molecule 1) as the endoplasmic reticulum-resident $\mathrm{Ca}^{2+}$ sensor and CRACM1 (calcium release-activated calcium modulator 1; also called Orai1) as the pore-forming subunit of CRAC channels ${ }^{2-6}$. STIM1 has one homolog, STIM2, whereas CRACM1 has two homologous proteins, CRACM2 and CRACM3, in mice and humans.

The canonical transient receptor potential (TRPC) channels have also been reported to increase intracellular $\mathrm{Ca}^{2+}$ concentrations either directly through coupled plasma membrane receptor stimulation or, arguably, through 'store depletion', in different cell types ${ }^{7-9}$. Of the seven mammalian TRPC channels (TRPC1-TRPC7), TRPC1 has most often been reported to form diverse channels, ranging from relatively $\mathrm{Ca}^{2+}$ selective to nonselective, in a variety of cell types by selective homomeric or heteromeric interactions with TRPC3, TRPC4 and TRPC7 (refs. ${ }^{10,11}$ ). In their non-store-operated mode, TRPC3, TRPC6 and TRPC7 can also be activated by diacylglycerol ${ }^{8,12,13}$. Direct involvement of TRPCs in SOCE remains

Correspondence should be addressed to M.V. (mvig@bidmc.harvard.edu).

COMPETING INTERESTS STATEMENT

The authors declare competing financial interests: details accompany the full-text HTML version of the paper at http://www.nature.com/natureimmunology/.

Reprints and permissions information is available online at http://npg.nature.com/reprintsandpermissions/ 
controversial with no conclusive reports of store-operated TRPC Ca ${ }^{2+}$ currents in lymphocytes. The evidence and controversies surrounding the function of TRPC channels in SOCE have been discussed ${ }^{1,11}$. There are many other non-store-operated routes of lymphocyte $\mathrm{Ca}^{2+}$ entry and modulators of lymphocyte cytosolic $\mathrm{Ca}^{2+}$ concentration (summary, Table 1 and Fig. 1).

\section{SOC influx during antigen receptor signaling}

Antigen recognition in lymphocytes typically results in the tyrosine phosphorylation of immunoreceptor tyrosine-based activation motifs and the recruitment and activation of protein tyrosine kinases. These initial signaling events, which are more or less similar in T and B lymphocytes and mast cells, trigger the phosphorylation and activation of phospholipase $\mathrm{C}$, which generates $\operatorname{Ins}(1,4,5) \mathrm{P}_{3}$ and diacylglycerol. $\operatorname{Ins}(1,4,5) \mathrm{P}_{3}$-induced release of $\mathrm{Ca}^{2+}$ from the endoplasmic reticulum results in a transient increase in the cytosolic free $\mathrm{Ca}^{2+}$ concentration, and diacylglycerol activates protein kinase $\mathrm{C}$. Protein kinase $\mathrm{C}$ and $\mathrm{Ca}^{2+}$ together initiate certain rapid cellular responses, such as rearrangement of the actin cytoskeleton to promote T cell motility, adhesion and formation of the immunological synapse, although maintenance of the immunological synapse probably requires a prolonged increase in the cytosolic $\mathrm{Ca}^{2+}$ concentration as a result of $\mathrm{SOCE}^{14}$. Diacylglycerol can accomplish several other functions, including directly activating non-store-operated $\mathrm{Ca}^{2+}$ influx through certain TRPC channels and stimulating the GTPase Ras-mitogen-activated protein kinase signaling cascade, which subsequently activates the AP-1 transcriptional complex ${ }^{8,12}$. In lymphocytes, AP-1 acts together with the transcription factors NFAT and NF- $\mathrm{KB}$ to modulate gene expression ${ }^{15} . \mathrm{Ca}^{2+}$ influx mediated by CRAC channels may also directly activate the Ras-mitogen-activated protein kinase cascade and thus also promote AP- 1 activation ${ }^{16}$. Other transcriptional regulators that depend on $\mathrm{Ca}^{2+}$ signaling for lymphocyte activation include NFAT, NF- $\kappa B$, the kinase Jnk and calmodulin-dependent kinase, although the duration and amplitude of cytosolic $\mathrm{Ca}^{2+}$ flux required for activation of each transcription factor varies ${ }^{17}$, 18. For example, a prolonged increase in cytosolic $\mathrm{Ca}^{2+}$ concentration via the CRAC channels is crucial for the activation of calcineurin, a serine-threonine phosphatase needed for the dephosphorylation and nuclear localization of NFAT. Even after its translocation into the nucleus, NFAT requires a sustained increase in $\mathrm{Ca}^{2+}$ concentration to prevent its ejection ${ }^{19}$. Several other cytosolic and nuclear factors modulate the intracellular localization of NFAT. These include the calcineurin inhibitors AKAP, CABIN, CHP and DSCR1, the newly identified Homer family proteins and the NFAT kinases GSK3, CK1 and DYRK ${ }^{19,20}$. Thus, the SOCE-calcineurin-NFAT pathway acts together with several other signaling cascades to promote lymphocyte antigen receptor-induced gene transcription.

\section{STIM proteins}

STIM1 is a 77-kilodalton single-spanning transmembrane protein that resides mainly in the endoplasmic reticulum and to some extent also in the plasma membrane. STIM1 has been proposed to sense the depletion of $\mathrm{Ca}^{2+}$ stores through its amino-terminal $\mathrm{Ca}^{2+}$-binding EF hand domain. Store depletion triggers the formation of oligomers of STIM1 in the endoplasmic reticulum through the EF-SAM region and subsequent translocation to discrete 'puncta' at endoplasmic reticulum-plasma membrane junctions ${ }^{21,22}$. Structural insights into the mechanism of the formation of oligomers have shown that in resting, $\mathrm{Ca}^{2+}$-replete conditions, the EF-SAM domain exists as a well-folded monomer. $\mathrm{Ca}^{2+}$ depletion induces partial unfolding and exposure of hydrophobic residues in the EF-SAM region, which results in its formation of oligomers ${ }^{23}$. Consistent with those findings, forced formation of heterodimers of STIM1 results in $\mathrm{Ca}^{2+}$-independent punctae formation and activation of $\mathrm{CRAC}^{2,24,25}$. The coiled-coil domains of STIM1, which mediate constitutive homotypic interactions, may further stabilize the EF-SAM-triggered oligomers and promote the translocation of STIM1 to endoplasmic reticulum-plasma membrane junctions ${ }^{26}$. The exact mechanism by which STIM1 oligomers 
activate CRAC channels once located in the endoplasmic reticulum-plasma membrane junctional region still remains to be determined.

STIM1 has a closely related homolog, STIM2. The function of STIM2 has remained somewhat controversial, with some early reports assigning it a positive function in SOCE and others suggesting a negative regulatory function ${ }^{2,27}$. A subsequent report has confirmed that STIM1 and STIM2 are activators of SOCE in HeLa cervical cancer cells, human embryonic kidney 293 cells and human umbilical vein endothelial cells ${ }^{28}$. More notably, knockdown of STIM1 or STIM2 expression mediated by small interfering RNA has shown that STIM2, but not STIM1, regulates mainly basal cytosolic and endoplasmic reticulum $\mathrm{Ca}^{2+}$ concentrations in these cells ${ }^{28}$. The authors suggest that to maintain basal $\mathrm{Ca}^{2+}$ concentrations, STIM2 has a $\mathrm{Ca}^{2+}$-binding EF hand domain with a lower affinity for $\mathrm{Ca}^{2+}$ than that of STIM1. As a result, even a small decrease in the endoplasmic reticulum $\mathrm{Ca}^{2+}$ concentration results in the translocation of STIM2 to endoplasmic reticulum-plasma membrane junctions to activate CRAC channels. In contrast to that report ${ }^{28}$, no obvious changes in the basal cytosolic $\mathrm{Ca}^{2+}$ or endoplasmic reticulum $\mathrm{Ca}^{2+}$ pools have been detected in ex vivo naive or in vitrodifferentiated T cells isolated from Stim $2^{-1-}$ mice, whereas naive Stim ${ }^{-1-} \mathrm{T}$ cells seem to have less release of endoplasmic reticulum $\mathrm{Ca}^{2+}$ induced by antibody to $\mathrm{CD} 3$, which indicates that Stiml ${ }^{-1-}$ cells have depleted resting endoplasmic reticulum $\mathrm{Ca}^{2+}$ pools ${ }^{29}$.

Similarly, mast cells derived from Stim $1^{-1-}$ mice have much less antigen- or thapsigarginstimulated release of endoplasmic reticulum $\mathrm{Ca}^{2+}$ than do Stim ${ }^{+/+}$mast cells ${ }^{16}$. Although the size of resting endoplasmic reticulum $\mathrm{Ca}^{2+}$ pools in Stiml ${ }^{-/}$and Stiml ${ }^{+/+}$mast cells was not specifically assessed in that study ${ }^{16}$, as mentioned above, it seems likely that STIM1 is crucial for the replenishment of endoplasmic reticulum $\mathrm{Ca}^{2+}$ during the resting state in mast cells and $\mathrm{T}$ cells. Thus, although it is clear that both STIM1 and STIM2 contribute to the maintenance of intracellular $\mathrm{Ca}^{2+}$ concentrations, their exact physiological functions seem to be complex and may differ depending on the cell type and mechanism of activation.

\section{CRACM proteins}

CRACM1 is a small protein of 32.7 kilodaltons with four transmembrane domains and amino and carboxyl ends that face the cytosol ${ }^{4-6}$. One of the first experiments to test whether CRACM1 could form the CRAC channel involved expressing CRACM1 together with STIM1 in human embryonic kidney and Jurkat cell lines. This resulted in an enormous amplification of 50- to 100-fold in CRAC currents ${ }^{6,30-32}$. Further biochemical analysis, including coimmunoprecipitation and site-directed mutagenesis of negatively charged transmembrane glutamate residues, has shown that CRACM1 creates the pore of the CRAC channel by forming homo-oligomers ${ }^{33-35}$. In experiments with heterologous expression systems, CRACM1 can also form heteropolymers with CRACM2 (Orai2) and CRACM3 (Orai3) and possibly some TRPC channel subunits ${ }^{36,37}$. A functional CRAC channel pore requires the tetrameric assembly of CRACM subunits. This has been shown by coexpression of preassembled tandem CRACM1 multimers composed of varying numbers of subunits along with a dominant negative CRACM1 mutant ${ }^{38,39}$.

\section{Communication between STIM1 and CRACM1}

A strong functional interaction between STIM1 and CRACM1 was demonstrated by many laboratories ${ }^{30-32}$. Such studies suggest that STIM1 and CRACM1 are necessary and sufficient to generate CRAC-like currents in vitro. Additional interacting molecules are either not required or are not limiting for the in vitro reconstitution of CRAC currents. After store depletion, STIM1 forms oligomers, moves to the endoplasmic reticulum-plasma membrane junctions and localizes within $10-25 \mathrm{~nm}$ of the plasma membrane ${ }^{40}$. Furthermore, the STIM1 clusters in the endoplasmic reticulum-plasma membrane junctions are present near the regions 
of $\mathrm{Ca}^{+}$influx from the plasma membrane. Although much insight has been gained from heterologous expression studies of CRACM1 and STIM1, many basic questions remain unanswered. For example, does STIM1 associate directly with CRACM1 to activate $\mathrm{Ca}^{2+}$ influx or is the interaction mediated by accessory proteins? Is plasma membrane STIM1 involved in SOCE? Using coimmunoprecipitation and fluorescence resonance energy transfer, various groups have shown that drosophila as well as mammalian homologs of STIM1 and CRACM1 can localize together and associate with each other ${ }^{33,34,41-43}$, with only a few exceptions that have failed to detect any interaction ${ }^{44}$. In addition, store depletion can enhance the association between drosophila STIM and CRACM proteins ${ }^{34}$. Using chemically inducible bridges of varying lengths between endoplasmic reticulum and plasma membrane, one study has shown that the estimated protrusion of CRACM1 into the cytosol is between $11 \mathrm{~nm}$ and $14 \mathrm{~nm}$, whereas the STIM1 cytosolic tail measures only $6 \mathrm{~nm}$. Although those data do not rule out the possibility of direct interaction between CRACM1 and STIM1, it is possible that unlike STIM1, CRACM1 is part of a larger molecular complex and that accessory proteins serve the function of connecting the two molecules ${ }^{45}$. One candidate for this could be $\mathrm{Ca}^{2+}$-independent phospholipase $\mathrm{A}_{2}$, a component of the $\mathrm{Ca}^{2+}$-influx factor pathway ${ }^{46}$. In fact, a drosophila ortholog of $\mathrm{Ca}^{2+}{ }_{-}$-independent phospholipase $\mathrm{A}_{2}, \mathrm{CG} 6718$, has shown up as a fairly strong 'hit' in a genome-wide RNA-mediated interference screen for genes involved in regulating SOCE $^{4}$. However, the hypothesis noted above can be reconciled with earlier reports ${ }^{6,30-32}$ showing amplification of about 100-fold in CRAC currents induced by coexpression of only CRACM1 and STIM1 when other intracellular components contributing to SOCE are present in nonlimiting quantities.

In attempts to elucidate the molecular mechanism of activation of CRAC channels, extensive delineation of the domains of STIM1 has identified regions involved in targeting STIM1 to the endoplasmic reticulum-plasma membrane junction versus those involved in activation or CRACM1 binding 22,26,41,47. Some data indicate that the STIM1 carboxy-terminal cytosolic tail containing a conserved ezrin-radixin-moesin domain and a lysine-rich region is sufficient to constitutively activate CRAC currents in human embryonic kidney cells ${ }^{41}$. However, another study found the polycationic region to be dispensable for CRAC activation ${ }^{47}$. That study also reported that the coiled-coil domain is essential for STIM1 aggregation and the serine-proline domain is essential for targeting to the endoplasmic reticulum-plasma membrane junction ${ }^{47}$. Furthermore, others have proposed that the carboxy-terminal domain of STIM1 dynamically binds a putative coiled-coil domain in the carboxy-terminal tail of CRACM1 in a $\mathrm{Ca}^{2+}$ store-dependent way ${ }^{43}$. One group used chemical crosslinking and singlemolecule imaging of green fluorescent protein-tagged CRACM1 to show that CRACM1 exists as a dimer in resting conditions. Furthermore, expression of green fluorescent protein-tagged CRACM1 together with the carboxyl terminus of STIM1 induces the 'dimerization' of CRACM1 dimers, resulting in active tetrameric CRAC channels in a store-independent way ${ }^{48}$. Further studies in this direction will delineate the precise molecular domains and steps involved in CRAC channel gating.

\section{Functions of CRAC in mast cells}

Mast cells are the key effectors that work at the interface of innate and adaptive immune responses ${ }^{49}$. Although mast cells can be activated in many different ways and thus serve many different functions, crosslinking of the high-affinity immunoglobulin E receptor FceRI is the main mechanism of mast cell activation. Crosslinking of FceRI initiates two parallel pathways activated by the Src-family protein tyrosine kinases Lyn and Fyn. Until recently it was generally accepted that in mast cells the Lyn-Syk-membrane adaptor Lat-phospholipase $\mathrm{C}$ axis is the main contributor to $\mathrm{Ca}^{2+}$ mobilization, whereas the Fyn-adaptor Gab2-

phosphatidylinositol-3-OH kinase-protein kinase C axis controls degranulation. Notably, Sykdeficient mast cells show defects in $\mathrm{Ca}^{2+}$ mobilization as well as degranulation, which indicates 
that the two pathways are not entirely independent of each other ${ }^{50}$. One distinct point of convergence between the two pathways seems to be at the level of protein kinase $\mathrm{C}$ activation and the increase in the cytosolic $\mathrm{Ca}^{2+}$ concentration, both of which probably act in concert to activate degranulation. The importance of the increase in cytosolic $\mathrm{Ca}^{2+}$ concentrations to mast cell degranulation is well documented. However, a specific requirement for CRAC channelmediated $\mathrm{Ca}^{2+}$ influx has been evaluated only recently with mast cells derived from CRACM1and STIM1-knockout mice ${ }^{16,51}$.

Mast cells lacking either STIM1 or CRACM1 show a considerable defect in degranulation. FceRI-induced in vivo anaphylaxis is also strongly inhibited in CRACM1-knockout mice and is much lower in Stim $1^{+/-}$mice ${ }^{16,51}$. As the release of $\mathrm{Ca}^{2+}$ from the endoplasmic reticulum is similar in wild-type and CRACM1-knockout mast cells, CRAC-mediated $\mathrm{Ca}^{2+}$ influx is crucial for mast cell degranulation. Further support for the idea that CRAC channels are involved in mast cell degranulation and anaphylaxis comes from $\operatorname{Trpm} 4^{-{ }^{--}}$mice. TRPM4 (transient receptor potential, melastatin, member 4 ) is a $\mathrm{Ca}^{2+}$-activated nonselective cation channel that decreases the driving force for $\mathrm{Ca}^{2+}$ entry through CRAC channels by modulating the membrane potential ${ }^{52,53}$. Trpm $^{-1-}$ bone marrow-derived mast cells show more SOCE than their $\operatorname{Trpm} 4^{+/+}$counterparts do in response to Fc\&RI stimulation. Furthermore, bone marrow-derived mast cells from $\operatorname{Trpm} 4^{-/-}$mice show augmented degranulation and a more severe immunoglobulin E-mediated acute passive cutaneous anaphylactic response ${ }^{54}$. Degranulation involves the translocation, docking and fusion of granules with the plasma membrane. Therefore, it is possible that CRAC channel-mediated sub-plasmalemmal increases in the cytosolic $\mathrm{Ca}^{2+}$ concentration activate or amplify certain 'downstream' signaling pathways involved in granule secretion ${ }^{55}$ or simply promote granule exocytosis by binding to $\mathrm{Ca}^{2+}$-sensing proteins, such as synaptotagmins, which are part of the SNARE complex involved in membrane fusion ${ }^{56}$. Unexpectedly, leukotriene secretion is also strongly inhibited in CRACM1-knockout mice, which suggests the involvement of CRAC channels in the secretion of proinflammatory lipid mediators ${ }^{51}$. Increases in cytosolic $\mathrm{Ca}^{2+}$ concentrations activate NFAT and NF- $\mathrm{kB}$, which regulate the transcription of genes encoding cytokines. It is therefore not unexpected that overall cytokine secretion is lower in CRACM1-knockout and Stim $1^{-/-}$mast cells and augmented in $\operatorname{Trpm}^{-/-}$mast cells. However, careful analysis shows that individual cytokines are affected differently. For example, secretion of tumor necrosis factor is much lower in Stim $1^{-/-}$and CRACM1-knockout mast cells and higher in Trpm4 $4^{-1-}$ mast cells. However, secretion of interleukin 6 is much lower, less affected or unaffected in Stim1 $1^{-1-}$, CRACM1-knockout or Trpm $4^{-1-}$ mast cells, respectively ${ }^{16,51,54}$. Secretion of interleukin 6 in mast cells depends on nuclear translocation of NF- $\mathrm{KB}^{57}$, which in turn depends on a large transient increase in the cytosolic $\mathrm{Ca}^{2+}$ concentration. NFAT translocation, however, requires a more sustained increase in $\mathrm{Ca}^{2+}$. It is likely that the smaller basal endoplasmic reticulum $\mathrm{Ca}^{2+}$ pools in $\mathrm{Stiml}^{-/-}$mast cells fail to provide the required large transient increase in cytosolic $\mathrm{Ca}^{2+}$ concentrations and thus result in less secretion of interleukin 6 (ref. ${ }^{16}$ ). In agreement with that hypothesis, CRACM1-deficient and $\operatorname{Trpm}^{-1-}$ mast cells show no substantial change in resting endoplasmic reticulum $\mathrm{Ca}^{2+}$ pools ${ }^{16,51,54}$. Therefore, it is possible that other CRACM homologs or store-operated channels are involved in maintaining the basal cytosolic and resting endoplasmic reticulum $\mathrm{Ca}^{2+}$ concentrations in mast cells. Such a scenario would also be consistent with the general idea that STIM1 acts as a global store sensor and activator of all store-operated channels.

Notably, CRACM1-knockout and Stim1 $1^{-1-}$ mast cells show no defects in proliferation or differentiation in vitro, and tissue mast cell numbers in CRACM1-knockout and Stim $1^{-1-}$ mice are similar to those in wild-type mice. These data suggest that a non-store-operated mode of $\mathrm{Ca}^{2+}$ entry may be crucial for the differentiation and proliferation of mast cells, but SOCE is not. 


\section{Calcium signaling in thymocytes}

Calcium signaling has long been proposed to be crucial for thymocyte maturation. Early studies using cyclosporine A (a calcineurin inhibitor) showed impaired development of $\mathrm{CD} 4^{+} \mathrm{CD} 8^{+}$ double-positive thymocytes into $\mathrm{CD} 4^{+} \mathrm{CD} 8^{-}$or $\mathrm{CD} 4^{-} \mathrm{CD} 8^{+}$single-positive thymocytes, as well as defects in thymocyte negative selection ${ }^{58,59}$. In addition, targeted disruption of the catalytic subunit (calcineurin $A \beta)^{60}$ as well as the regulatory subunit (calcineurin B1) ${ }^{61}$ of calcineurin results in a distinct defect in positive selection, with fewer single-positive cells, although negative selection seems normal ${ }^{61}$. Similarly, disruption of NFATc3, which is 'preferentially' expressed in double-positive thymocytes, results in fewer single-positive thymocytes and is associated with defects in expression of the antiapoptosis protein Bcl-2 by double-positive cells ${ }^{62}$. Notably, CRACM1-deficient and Stiml $1^{-1-}$ Stim2 $^{-1-}$ mice show no defect in the thymic development of conventional $\mathrm{T}$ cells $\mathrm{s}^{29,51,63}$. These observations are unexpected, given the reports described above linking calcium-calcineurin-NFAT signaling to $\mathrm{T}$ cell development.

As CRACM1 has two closely related homologs (CRACM2 and CRACM3), one obvious issue that arises from the studies discussed above is whether CRACM2 and/or CRACM3 form functional channels to recruit $\mathrm{Ca}^{2+}$ in thymocytes. Both CRACM2 and CRACM3 have been shown to be able to conduct CRAC currents in in vitro overexpression systems ${ }^{36,64}$. Indeed, CRACM2 mRNA is much more abundant than CRACM1 mRNA in wild-type mouse thymocytes ${ }^{51}$. Moreover, the lymphoid regions of thymus and spleen in a 'gene-trap' CRACM1-deficient mouse are devoid of CRACM1 protein expression, as indicated by $\beta$ galactosidase reporter activity ${ }^{51}$, whereas another report has detected faint expression of CRACM1 protein in wild-type thymus and lymph nodes ${ }^{63}$. Thus, CRACM2 may be the dominant homolog in mouse thymocytes, different CRACM homologs may be expressed and function during different stages of $\mathrm{T}$ cell development and maturation, and/or thymocytes may use a non-store-operated method of sustaining $\mathrm{Ca}^{2+}$ signaling during positive selection. Further studies with CRACM2- and CRACM3-deficient mouse models should be able to test these various possibilities.

Notably, deletion of TRPM7 results in a block in thymocyte development at the CD4 ${ }^{-} \mathrm{CD} 8^{-}$ double-negative stage ${ }^{65}$. TRPM7 is a non-store-operated cation channel that conducts $\mathrm{Ca}^{2+}$ and $\mathrm{Mg}^{2+}$ ions and has an intrinsic kinase activity. Although the exact mechanism of this defect remains to be demonstrated, the $\mathrm{Mg}^{2+}$ homeostasis of TRPM7-deficient thymocytes seems to be normal ${ }^{65}$.

\section{CRAC channels in naive and differentiated T cells}

Since the discovery of the CRAC current, crucial functions for SOCE in all aspects of lymphocyte activation, including proliferation and cytokine secretion, have been proposed ${ }^{66}$, ${ }^{67}$. Moreover, analysis of peripheral blood lymphocytes ${ }^{68}$ and $\mathrm{T}$ cell lines ${ }^{69}$ derived from patients with severe combined immunodeficiency (SCID) who have a loss-of-function mutation in the gene encoding CRACM1 has identified defective T cell proliferation and cytokine secretion. Two independent analyses of CRACM1-deficient mice have provided several new insights into the function of CRAC channels in T cell activation. One group has used gene-trap technology to 'knock down' CRACM1 expression ${ }^{51}$, whereas the other group has generated CRACM1-deficient mice by targeted gene ablation ${ }^{63}$. Unexpectedly, naive $\mathrm{T}$ cell populations analyzed ex vivo show either no defect ${ }^{51}$ or an insubstantial decrease ${ }^{63}$ in SOC influx in the presence of physiological concentrations of extracellular $\mathrm{Ca}^{2+}$. Furthermore, proliferation is unaffected, although cytokine secretion by naive T lymphocytes is impaired in CRACM1-deficient mice ${ }^{51,63}$. In addition, thymocyte development is normal in CRACM1deficient mice $29,51,63$. Therefore, the phenotype of thymocytes and naive $\mathrm{T}$ cells from 
CRACM1-deficient mice contrasts considerably with the phenotype of $\mathrm{T}$ cells from patients with SCID who have mutations in the gene encoding CRACM1 (refs. ${ }^{68,69}$ ). These differences may be due to species-specific dependency on CRACM1 and/or CRACM2 and CRACM3. The other important difference is the activation status of the cells when naive $\mathrm{T}$ cells from CRACM1-deficient mice are compared with immortal $\mathrm{T}$ cell lines developed in vitro from human patients with SCID. Indeed, analysis of in vitro-differentiated helper T cell populations has reconciled some (but not all) of these phenotypic differences ${ }^{5,63,68,69}$. Differentiated helper T cells from CRACM1-deficient mice have much less SOC influx as well as cytokine release, although $\mathrm{T}$ cell proliferation remains unaffected, in contrast to the earlier reported proliferation defects in T cells from patients with SCID ${ }^{63,68,69}$.

It is unlikely that both of the strains of CRACM1-deficient mice described above are hypomorphic; thus, the other logical possibilities are discussed here. The higher expression of CRACM2 than of CRACM1 and CRACM3 mRNA in mouse thymocytes and naive T cells suggests that these populations may use CRACM2 as the dominant CRACM homolog to form the $\mathrm{Ca}^{2+}{ }_{\text {-recruiting SOC }}$ channel ${ }^{51}$. In agreement with that hypothesis, relatively less CRACM2 mRNA is detected in the in vitro-differentiated helper T cell subsets ${ }^{63}$. Another possibility is that, as reported for TRPC channels, CRACM homologs may form distinct heteromultimeric CRAC channels in vivo with variable cell- or tissue-specific composition. Thus, the expression of CRACM homologs and/or the composition of CRAC channels in T cells may vary with the differentiation status of the cell. Although CRACM2 has been reported to result in store-operated currents when overexpressed with STIM1 (refs. ${ }^{36,64}$ ), it is important to note that the biophysical and pharmacological properties of the resulting currents are distinct from those of native CRAC channels. CRACM homologs also presumably have different activation thresholds and $\mathrm{Ca}^{2+}$-dependent inactivation properties ${ }^{36,64}$. As these differences may not be apparent in assays using fluorescence-based $\mathrm{Ca}^{2+}$ indicators (such as Fura-2), direct recording from developing and naive $\mathrm{T}$ cells, although challenging, is crucial and may provide insights into the exact route of $\mathrm{Ca}^{2+}$ influx in these $\mathrm{T}$ cell populations.

Another independent observation that supports the hypothesis outlined above is that STIM2 expression, although negligible in naive T cells, is higher in helper $\mathrm{T}$ cells differentiated in vitro $^{29}$. Moreover, the hypothesis that STIM2 translocates to endoplasmic reticulum-plasma membrane junctions to activate CRAC channels after sensing even a slight depletion in endoplasmic reticulum $\mathrm{Ca}^{2+}$ stores ${ }^{28}$ fits well with the finding that antigen-experienced, differentiated or memory $\mathrm{T}$ cell populations require a relatively suboptimal stimulus to trigger cytokine release. We have provided a summary of the proposed expression pattern for STIM and CRACM homologs on the basis of published and unpublished data (Fig. 2). Notably, Stim $1^{-l-}$ Stim $2^{-/-}$mice show no obvious defect in the thymic differentiation of conventional $\mathrm{T}$ cells and only a partial defect in the proliferation of naive T cells ${ }^{29}$. Given that STIM proteins are considered global activators of SOCE, these data also suggest that a non-store-operated method of $\mathrm{Ca}^{2+}$ influx may contribute to the regulation of $\mathrm{Ca}^{2+}$ signaling in naive $\mathrm{T}$ cells. However, Stim $1^{-1-}$ Stim $2^{---}$mice do have a defect in regulatory $\mathrm{T}$ cell numbers and develop lymphoproliferative disorders ${ }^{29}$. Such observations are consistent with the lymphocyte hyperproliferation reported in mice lacking both NFATc1 and NFATc2 (ref. ${ }^{70}$ ).

\section{Non-store-operated $\mathrm{Ca}^{2+}$ signaling in $\mathrm{T}$ cells}

$\mathrm{T}$ lymphocytes also express voltage-gated $\mathrm{Ca}^{2+}$ channels (Cav channels), but whether these channels are functional in lymphocytes remains debatable ${ }^{71,72}$. Cav channels are expressed and functional mainly in excitable cells such as neurons and muscle cells, where they are activated in response to membrane depolarization. $\mathrm{CD} 4^{+} \mathrm{T}$ cells lacking the Cav regulatory $\beta 4$ or $\beta 3$ subunits show impaired $\mathrm{Ca}^{2+}$ responses in response to stimulation of the $\mathrm{T}$ cell antigen receptor ${ }^{72}$. These $\mathrm{Ca}^{2+}$ responses seemed to be independent of the release of $\mathrm{Ca}^{2+}$ from 
endoplasmic reticulum stores, as no defect is found in response to thapsigargin, which mediates passive release of $\mathrm{Ca}^{2+}$ from the endoplasmic reticulum and activates CRAC channels. Nuclear translocation of both NFAT subtypes, NFATc2 and NFATc1, is inhibited in both $\beta$-subunitdeficient $\mathrm{T}$ cell strains, which shows that the entire calcium-calcineurin-NFAT pathway is affected. Although the proliferation of $\beta 4$-mutant CD4 T lymphocytes is intact, cytokine secretion from these cells is lower. These data collectively suggest that Cav channels are necessary for a normal $\mathrm{T}$ cell antigen receptor-mediated $\mathrm{Ca}^{2+}$ response in $\mathrm{CD}^{+} \mathrm{T}$ cells.

However, membrane depolarization does not result in the activation of Cav channels in $\mathrm{T}$ lymphocytes, which suggests the existence of an alternative gating mechanism for these channels $^{72}$. An independent study has shown that a carboxy-terminal fragment of Cav1.2 (also called the 'L-type voltage-gated calcium channel') can translocate to the nucleus and regulate transcription $^{73}$. This calcium channel-associated transcription regulator can bind to a nuclear protein and an endogenous promoter and to regulate the expression of a wide variety of genes essential for signaling and excitability in neurons. The nuclear localization of the calcium channel-associated transcription regulator is regulated by changes in intracellular $\mathrm{Ca}^{2+}$ concentrations, among other parameters. In summary, the operation and functional importance of store-independent modes of $\mathrm{Ca}^{2+}$ entry in lymphocytes remains to be determined.

\section{Conclusions}

Molecular and genetic approaches have demonstrated that components of the SOCE signaling pathway are crucial for the function of lymphocytes. However, several alternative routes of $\mathrm{Ca}^{2+}$ influx exist and may be implemented at various stages of the development and maturation of lymphocytes. Future studies of how individual lymphocyte types use different sources of $\mathrm{Ca}^{2+}$ influx during their lifespan should provide useful insights.

\section{Acknowledgments}

We thank P. Rao and D. Okuhara for discussions and J.W. Putney for critical reading of this manuscript, and we apologize to those colleagues whose work we could not cite because of space limitations. Supported by the Cancer Research Institute-Irvington Institute Fellowship Program (M.V.) and the US National Institutes of Health (GM 053950 to J.-P.K.).

\section{References}

1. Parekh AB, Putney JW Jr. Store-operated calcium channels. Physiol Rev 2005;85:757-810. [PubMed: 15788710]

2. Liou J, et al. STIM is a $\mathrm{Ca}^{2+}$ sensor essential for $\mathrm{Ca}^{2+}$-store-depletion-triggered $\mathrm{Ca}^{2+}$ influx. Curr Biol 2005;15:1235-1241. [PubMed: 16005298]

3. Zhang SL, et al. STIM1 is a $\mathrm{Ca}^{2+}$ sensor that activates CRAC channels and migrates from the $\mathrm{Ca}^{2+}$ store to the plasma membrane. Nature 2005;437:902-905. [PubMed: 16208375]

4. Vig M, et al. CRACM1 is a plasma membrane protein essential for store-operated $\mathrm{Ca}^{2+}$ entry. Science 2006;312:1220-1223. [PubMed: 16645049]

5. Feske $\mathrm{S}$, et al. A mutation in Orail causes immune deficiency by abrogating CRAC channel function. Nature 2006;441:179-185. [PubMed: 16582901]

6. Zhang SL, et al. Genome-wide RNAi screen of $\mathrm{Ca}^{2+}$ influx identifies genes that regulate $\mathrm{Ca}^{2+}$ releaseactivated $\mathrm{Ca}^{2+}$ channel activity. Proc Natl Acad Sci USA 2006;103:9357-9362. [PubMed: 16751269]

7. Philipp S, et al. TRPC3 mediates T-cell receptor-dependent calcium entry in human T-lymphocytes. J Biol Chem 2003;278:26629-26638. [PubMed: 12736256]

8. Venkatachalam K, Ma HT, Ford DL, Gill DL. Expression of functional receptor-coupled TRPC3 channels in DT40 triple receptor InsP3 knockout cells. J Biol Chem 2001;276:33980-33985. [PubMed: 11466302] 
9. Putney JW Jr. Capacitative calcium entry: sensing the calcium stores. J Cell Biol 2005;169:381-382. [PubMed: 15866892]

10. Yuan JP, Zeng W, Huang GN, Worley PF, Muallem S. STIM1 heteromultimerizes TRPC channels to determine their function as store-operated channels. Nat Cell Biol 2007;9:636-645. [PubMed: 17486119]

11. Villereal ML. Mechanism and functional significance of TRPC channel multimerization. Semin Cell Dev Biol 2006;17:618-629. [PubMed: 17158075]

12. Hardie RC. TRP channels and lipids: from Drosophila to mammalian physiology. J Physiol 2007;578:9-24. [PubMed: 16990401]

13. Rao GK, Kaminski NE. Induction of intracellular calcium elevation by Delta9-tetrahydrocannabinol in T cells involves TRPC1 channels. J Leukoc Biol 2006;79:202-213. [PubMed: 16244107]

14. Lioudyno MI, et al. Orai1 and STIM1 move to the immunological synapse and are up-regulated during T cell activation. Proc Natl Acad Sci USA 2008;105:2011-2016. [PubMed: 18250319]

15. Malek TR. The biology of interleukin-2. Annu Rev Immunol 2008;26:453-479. [PubMed: 18062768]

16. Baba Y, et al. Essential function for the calcium sensor STIM1 in mast cell activation and anaphylactic responses. Nat Immunol 2008;9:81-88. [PubMed: 18059272]

17. Dolmetsch RE, Lewis RS, Goodnow CC, Healy JI. Differential activation of transcription factors induced by $\mathrm{Ca}^{2+}$ response amplitude and duration. Nature 1997;386:855-858. [PubMed: 9126747]

18. Ho N, Gullberg M, Chatila T. Activation protein 1-dependent transcriptional activation of interleukin 2 gene by $\mathrm{Ca}^{2+} /$ calmodulin kinase type IV/Gr. J Exp Med 1996;184:101-112. [PubMed: 8691123]

19. Crabtree GR, Olson EN. NFAT signaling: choreographing the social lives of cells. Cell 2002;109:S67-S79. [PubMed: 11983154]

20. Huang GN, et al. NFAT binding and regulation of T cell activation by the cytoplasmic scaffolding Homer proteins. Science 2008;319:476-481. [PubMed: 18218901]

21. Stathopulos PB, Li GY, Plevin MJ, Ames JB, Ikura M. Stored $\mathrm{Ca}^{2+}$ depletion-induced oligomerization of stromal interaction molecule 1 (STIM1) via the EF-SAM region: an initiation mechanism for capacitive $\mathrm{Ca}^{2+}$ entry. J Biol Chem 2006;281:35855-35862. [PubMed: 17020874]

22. Liou J, Fivaz M, Inoue T, Meyer T. Live-cell imaging reveals sequential oligomerization and local plasma membrane targeting of stromal interaction molecule 1 after $\mathrm{Ca}^{2+}$ store depletion. Proc Natl Acad Sci USA 2007;104:9301-9306. [PubMed: 17517596]

23. Stathopulos PB, Zheng L, Li GY, Plevin MJ, Ikura M. Structural and mechanistic insights into STIM1mediated initiation of store-operated calcium entry. Cell 2008;135:110-122. [PubMed: 18854159]

24. Luik RM, Wu MM, Buchanan J, Lewis RS. The elementary unit of store-operated $\mathrm{Ca}^{2+}$ entry: local activation of CRAC channels by STIM1 at ER-plasma membrane junctions. J Cell Biol 2006;174:815-825. [PubMed: 16966423]

25. Luik RM, Wang B, Prakriya M, Wu MM, Lewis RS. Oligomerization of STIM1 couples ER calcium depletion to CRAC channel activation. Nature 2008;454:538-542. [PubMed: 18596693]

26. Baba Y, et al. Coupling of STIM1 to store-operated $\mathrm{Ca}^{2+}$ entry through its constitutive and inducible movement in the endoplasmic reticulum. Proc Natl Acad Sci USA 2006;103:16704-16709. [PubMed: 17075073]

27. Soboloff J, et al. STIM2 is an inhibitor of STIM1-mediated store-operated $\mathrm{Ca}^{2+}$ entry. Curr Biol 2006;16:1465-1470. [PubMed: 16860747]

28. Brandman O, Liou J, Park WS, Meyer T. STIM2 is a feedback regulator that stabilizes basal cytosolic and endoplasmic reticulum $\mathrm{Ca}^{2+}$ levels. Cell 2007;131:1327-1339. [PubMed: 18160041]

29. Oh-Hora M, et al. Dual functions for the endoplasmic reticulum calcium sensors STIM1 and STIM2 in T cell activation and tolerance. Nat Immunol 2008;9:432-443. [PubMed: 18327260]

30. Peinelt C, et al. Amplification of CRAC current by STIM1 and CRACM1 (Orai1). Nat Cell Biol 2006;8:771-773. [PubMed: 16733527]

31. Mercer JC, et al. Large store-operated calcium selective currents due to co-expression of Orai1 or Orai2 with the intracellular calcium sensor, Stim1. J Biol Chem 2006;281:24979-24990. [PubMed: 16807233]

32. Soboloff J, et al. Orai1 and STIM reconstitute store-operated calcium channel function. J Biol Chem 2006;281:20661-20665. [PubMed: 16766533] 
33. Vig M, et al. CRACM1 multimers form the ion-selective pore of the CRAC channel. Curr Biol 2006;16:2073-2079. [PubMed: 16978865]

34. Yeromin AV, et al. Molecular identification of the CRAC channel by altered ion selectivity in a mutant of Orai. Nature 2006;443:226-229. [PubMed: 16921385]

35. Prakriya M, et al. Orai1 is an essential pore subunit of the CRAC channel. Nature 2006;443:230-233. [PubMed: 16921383]

36. Lis A, et al. CRACM1, CRACM2, and CRACM3 are store-operated $\mathrm{Ca}^{2+}$ channels with distinct functional properties. Curr Biol 2007;17:794-800. [PubMed: 17442569]

37. Ong HL, et al. Dynamic assembly of TRPC1-STIM1-Orai1 ternary complex is involved in storeoperated calcium influx. Evidence for similarities in store-operated and calcium release-activated calcium channel components. J Biol Chem 2007;282:9105-9116. [PubMed: 17224452]

38. Mignen O, Thompson JL, Shuttleworth TJ. Orai1 subunit stoichiometry of the mammalian CRAC channel pore. J Physiol 2008;586:419-425. [PubMed: 18006576]

39. Ji W, et al. Functional stoichiometry of the unitary calcium-release-activated calcium channel. Proc Natl Acad Sci USA 2008;105:13668-13673. [PubMed: 18757751]

40. Wu MM, Buchanan J, Luik RM, Lewis RS. $\mathrm{Ca}^{2+}$ store depletion causes STIM1 to accumulate in ER regions closely associated with the plasma membrane. J Cell Biol 2006;174:803-813. [PubMed: 16966422]

41. Huang GN, et al. STIM1 carboxyl-terminus activates native SOC, $I_{\text {crac }}$ and TRPC1 channels. Nat Cell Biol 2006;8:1003-1010. [PubMed: 16906149]

42. Barr VA, et al. Dynamic movement of the calcium sensor STIM1 and the calcium channel Orai1 in activated T-cells: puncta and distal caps. Mol Biol Cell 2008;19:2802-2817. [PubMed: 18448669]

43. Muik M, et al. Dynamic coupling of the putative coiled-coil domain of ORAI1 with STIM1 mediates ORAI1 channel activation. J Biol Chem 2008;283:8014-8022. [PubMed: 18187424]

44. Gwack Y, et al. Biochemical and functional characterization of Orai proteins. J Biol Chem 2007;282:16232-16243. [PubMed: 17293345]

45. Varnai P, Toth B, Toth DJ, Hunyady L, Balla T. Visualization and manipulation of plasma membraneendoplasmic reticulum contact sites indicates the presence of additional molecular components within the STIM1-Orail complex. J Biol Chem 2007;282:29678-29690. [PubMed: 17684017]

46. Smani T, et al. A novel mechanism for the store-operated calcium influx pathway. Nat Cell Biol 2004;6:113-120. [PubMed: 14730314]

47. $\mathrm{Li} \mathrm{Z}$, et al. Mapping the interacting domains of STIM1 and Orai1 in $\mathrm{Ca}^{2+}$ release-activated $\mathrm{Ca}^{2+}$ channel activation. J Biol Chem 2007;282:29448-29456. [PubMed: 17702753]

48. Penna A, et al. The CRAC channel consists of a tetramer formed by STIM-induced dimerization of Orai dimers. Nature 2008;456:116-120. [PubMed: 18820677]

49. Leslie M. Mast cells show their might. Science 2007;317:614-616. [PubMed: 17673649]

50. Nadler MJ, Kinet JP. Uncovering new complexities in mast cell signaling. Nat Immunol 2002;3:707708. [PubMed: 12145654]

51. Vig M, et al. Defective mast cell effector functions in mice lacking the CRACM1 pore subunit of store-operated calcium release-activated calcium channels. Nat Immunol 2008;9:89-96. [PubMed: 18059270]

52. Launay $\mathrm{P}$, et al. TRPM4 is a $\mathrm{Ca}^{2+}$-activated nonselective cation channel mediating cell membrane depolarization. Cell 2002;109:397-407. [PubMed: 12015988]

53. Launay P, et al. TRPM4 regulates calcium oscillations after T cell activation. Science 2004;306:13741377. [PubMed: 15550671]

54. Vennekens R, et al. Increased IgE-dependent mast cell activation and anaphylactic responses in mice lacking the calcium-activated nonselective cation channel TRPM4. Nat Immunol 2007;8:312-320. [PubMed: 17293867]

55. Chang WC, et al. Local $\mathrm{Ca}^{2+}$ influx through $\mathrm{Ca}^{2+}$ release-activated $\mathrm{Ca}^{2+}(\mathrm{CRAC})$ channels stimulates production of an intracellular messenger and an intercellular pro-inflammatory signal. J Biol Chem 2008;283:4622-4631. [PubMed: 18156181]

56. Rettig J, Neher E. Emerging roles of presynaptic proteins in $\mathrm{Ca}^{++}$-triggered exocytosis. Science 2002;298:781-785. [PubMed: 12399579] 
57. Kalesnikoff J, et al. SHIP negatively regulates IgE + antigen-induced IL-6 production in mast cells by inhibiting NF- $\kappa B$ activity. J Immunol 2002;168:4737-4746. [PubMed: 11971024]

58. Jenkins MK, Schwartz RH, Pardoll DM. Effects of cyclosporine A on T cell development and clonal deletion. Science 1988;241:1655-1658. [PubMed: 3262237]

59. Gao EK, Lo D, Cheney R, Kanagawa O, Sprent J. Abnormal differentiation of thymocytes in mice treated with cyclosporin A. Nature 1988;336:176-179. [PubMed: 2972933]

60. Bueno OF, Brandt EB, Rothenberg ME, Molkentin JD. Defective T cell development and function in calcineurin A $\beta$-deficient mice. Proc Natl Acad Sci USA 2002;99:9398-9403. [PubMed: 12091710]

61. Neilson JR, Winslow MM, Hur EM, Crabtree GR. Calcineurin B1 is essential for positive but not negative selection during thymocyte development. Immunity 2004;20:255-266. [PubMed: 15030770]

62. Oukka M, et al. The transcription factor NFAT4 is involved in the generation and survival of T cells. Immunity 1998;9:295-304. [PubMed: 9768749]

63. Gwack Y, et al. Hair loss and defective T and B cell function in mice lacking ORAI1. Mol Cell Biol. 2008

64. DeHaven WI, Smyth JT, Boyles RR, Putney JW Jr. Calcium inhibition and calcium potentiation of Orai1, Orai2, and Orai3 calcium release-activated calcium channels. J Biol Chem 2007;282:1754817556. [PubMed: 17452328]

65. Jin J, et al. Deletion of Trpm7 disrupts embryonic development and thymopoiesis without altering $\mathrm{Mg}^{2+}$ homeostasis. Science 2008;322:756-760. [PubMed: 18974357]

66. Lewis RS, Cahalan MD. Mitogen-induced oscillations of cytosolic $\mathrm{Ca}^{2+}$ and transmembrane $\mathrm{Ca}^{2+}$ current in human leukemic T cells. Cell Regul 1989;1:99-112. [PubMed: 2519622]

67. Zweifach A, Lewis RS. Mitogen-regulated $\mathrm{Ca}^{2+}$ current of $\mathrm{T}$ lymphocytes is activated by depletion of intracellular $\mathrm{Ca}^{2+}$ stores. Proc Natl Acad Sci USA 1993;90:6295-6299. [PubMed: 8392195]

68. Partiseti M, et al. The calcium current activated by $\mathrm{T}$ cell receptor and store depletion in human lymphocytes is absent in a primary immunodeficiency. J Biol Chem 1994;269:32327-32335. [PubMed: 7798233]

69. Feske S, et al. Severe combined immunodeficiency due to defective binding of the nuclear factor of activated T cells in T lymphocytes of two male siblings. Eur J Immunol 1996;26:2119-2126. [PubMed: 8814256]

70. Peng SL, Gerth AJ, Ranger AM, Glimcher LH. NFATc1 and NFATc2 together control both T and B cell activation and differentiation. Immunity 2001;14:13-20. [PubMed: 11163226]

71. Kotturi MF, Hunt SV, Jefferies WA. Roles of CRAC and Cav-like channels in T cells: more than one gatekeeper? Trends Pharmacol Sci 2006;27:360-367. [PubMed: 16766050]

72. Badou A, et al. Critical role for the $\beta$ regulatory subunits of Cav channels in Tymphocyte function. Proc Natl Acad Sci USA 2006;103:15529-15534. [PubMed: 17028169]

73. Gomez-Ospina N, Tsuruta F, Barreto-Chang O, Hu L, Dolmetsch R. The C terminus of the L-type voltage-gated calcium channel Cav1.2 encodes a transcription factor. Cell 2006;127:591-606. [PubMed: 17081980]

74. Gouy H, Cefai D, Christensen SB, Debre P, Bismuth G. $\mathrm{Ca}^{2+}$ influx in human T lymphocytes is induced independently of inositol phosphate production by mobilization of intracellular $\mathrm{Ca}^{2+}$ stores. A study with the $\mathrm{Ca}^{2+}$ endoplasmic reticulum-ATPase inhibitor thapsigargin. Eur J Immunol 1990;20:2269-2275. [PubMed: 1700752]

75. Telford WG, Miller RA. Detection of plasma membrane $\mathrm{Ca}^{2+}$-ATPase activity in mouse $\mathrm{T}$ lymphocytes by flow cytometry using fluo-3-loaded vesicles. Cytometry 1996;24:243-250. [PubMed: 8800557]

76. Bautista DM, Hoth M, Lewis RS. Enhancement of calcium signalling dynamics and stability by delayed modulation of the plasma-membrane calcium-ATPase in human T cells. J Physiol (Lond) 2002;541:877-894. [PubMed: 12068047]

77. Jayaraman T, Ondriasova E, Ondrias K, Harnick DJ, Marks AR. The inositol 1,4,5-trisphosphate receptor is essential for T-cell receptor signaling. Proc Natl Acad Sci USA 1995;92:6007-6011. [PubMed: 7597070] 
78. Guse AH, et al. Regulation of calcium signalling in $\mathrm{T}$ lymphocytes by the second messenger cyclic ADP-ribose. Nature 1999;398:70-73. [PubMed: 10078531]

79. Sei Y, Gallagher KL, Basile AS. Skeletal muscle type ryanodine receptor is involved in calcium signaling in human B lymphocytes. J Biol Chem 1999;274:5995-6002. [PubMed: 10026226]

80. Guerini D, Coletto L, Carafoli E. Exporting calcium from cells. Cell Calcium 2005;38:281-289. [PubMed: 16102821]

81. Balasubramanyam M, Rohowsky-Kochan C, Reeves JP, Gardner JP. $\mathrm{Na}^{+} / \mathrm{Ca}^{2+}$ exchange-mediated calcium entry in human lymphocytes. J Clin Invest 1994;94:2002-2008. [PubMed: 7962546]

82. Saris NE, Carafoli E. A historical review of cellular calcium handling, with emphasis on mitochondria. Biochemistry (Mosc) 2005;70:187-194. [PubMed: 15807658]

83. Hoth M, Fanger CM, Lewis RS. Mitochondrial regulation of store-operated calcium signaling in $\mathrm{T}$ lymphocytes. J Cell Biol 1997;137:633-648. [PubMed: 9151670]

84. Beeton C, Chandy KG. Potassium channels, memory T cells, and multiple sclerosis. Neuroscientist 2005;11:550-562. [PubMed: 16282596]

85. Cowen DS, et al. Extracellular adenosine triphosphate activates calcium mobilization in human phagocytic leukocytes and neutrophil/monocyte progenitor cells. J Clin Invest 1989;83:1651-1660. [PubMed: 2708526]

86. Cui J, Bian JS, Kagan A, McDonald TV. CaT1 contributes to the stores-operated calcium current in Jurkat T-lymphocytes. J Biol Chem 2002;277:47175-47183. [PubMed: 12361955]

87. Perraud AL, et al. ADP-ribose gating of the calcium-permeable LTRPC2 channel revealed by Nudix motif homology. Nature 2001;411:595-599. [PubMed: 11385575]

88. Sano Y, et al. Immunocyte $\mathrm{Ca}^{2+}$ influx system mediated by LTRPC2. Science 2001;293:1327-1330. [PubMed: 11509734]

89. Nadler MJ, et al. LTRPC7 is a Mg. ATP-regulated divalent cation channel required for cell viability. Nature 2001;411:590-595. [PubMed: 11385574]

90. Prakriya M, Lewis RS. Separation and characterization of currents through store-operated CRAC channels and $\mathrm{Mg}^{2+}$-inhibited cation (MIC) channels. J Gen Physiol 2002;119:487-507. [PubMed: 11981025]

91. Shuttleworth TJ. What drives calcium entry during $\left[\mathrm{Ca}^{2+}\right]$ i oscillations? -challenging the capacitative model. Cell Calcium 1999;25:237-246. [PubMed: 10378085]

92. Dellis O, et al. $\mathrm{Ca}^{2+}$ entry through plasma membrane IP3 receptors. Science 2006;313:229-233. [PubMed: 16840702] 

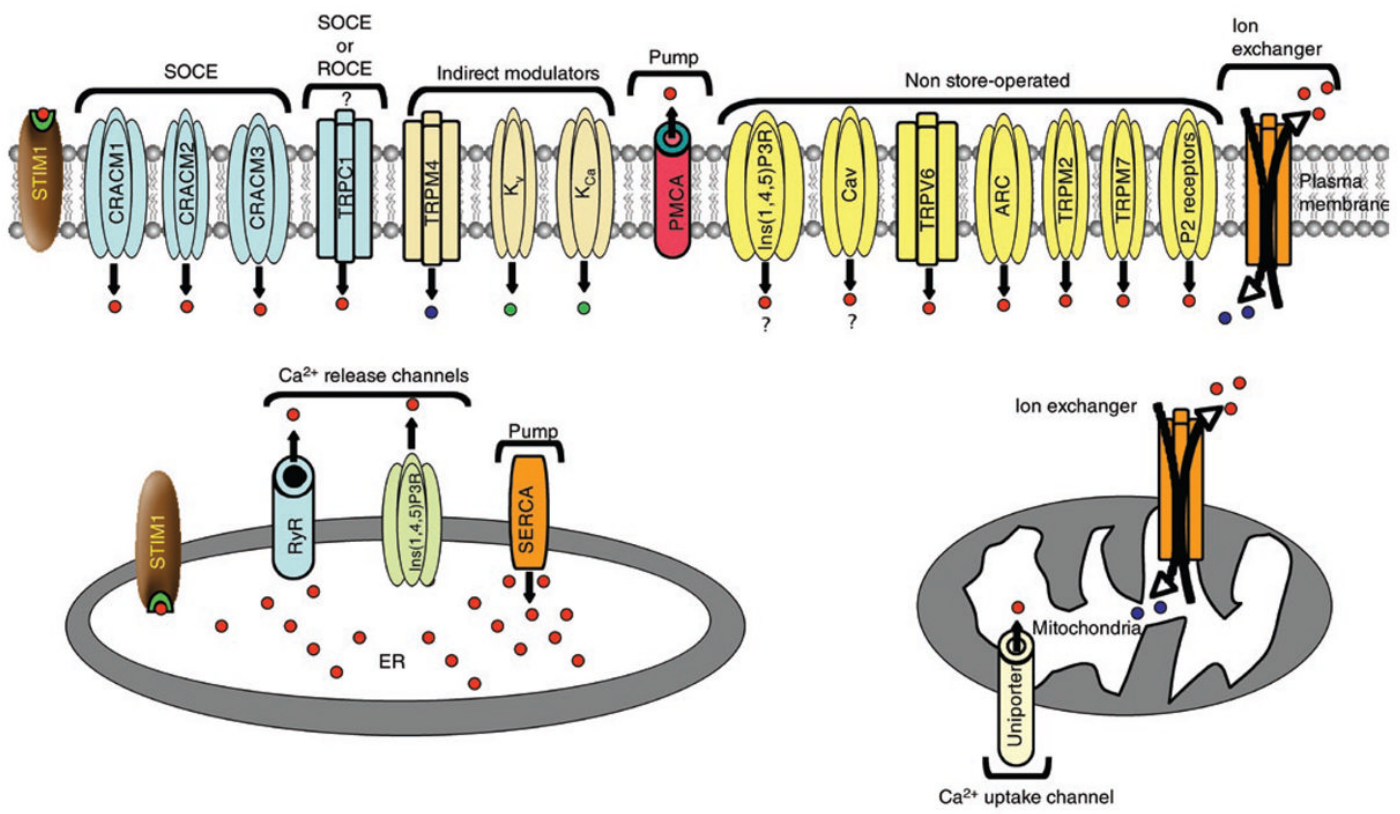

Figure 1.

Routes of $\mathrm{Ca}^{2+}$ influx and efflux. Routes with similar mechanisms of activation are grouped together here. The probability of activation of a particular mechanism and its eventual contribution toward an increase in cytosolic $\mathrm{Ca}^{2+}$ may vary, and all routes may not be active at a given time. Red dots, $\mathrm{Ca}^{2+}$; blue dots, $\mathrm{Na}^{+}$; green dots, $\mathrm{K}^{+}$; ?, controversial route. ROCE, receptor-operated $\mathrm{Ca}^{2+}$ entry; $\mathrm{K}_{\mathrm{v}}$, voltage-gated $\mathrm{K}^{+}$channel; $\mathrm{K}_{\mathrm{Ca}}, \mathrm{Ca}^{2+}$-activated $\mathrm{K}^{+}$channel; PMCA, plasma membrane $\mathrm{Ca}^{2+}$ ATPase; Ins $(1,4,5) \mathrm{P}_{3} \mathrm{R}$, Ins $(1,4,5) \mathrm{P}_{3}$ receptor; TRPV6, transient receptor potential, vanilloid, member 6; ARC, arachidonate-regulated, $\mathrm{Ca}^{2+}$ selective; P2 receptors, purinergic receptors; RyR, ryanodine receptor; SERCA, sarcoendoplasmic reticulum $\mathrm{Ca}^{2+}$ ATPase; ER, endoplasmic reticulum. 
Mouse

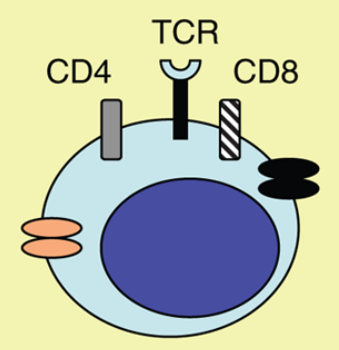

DP thymocyte
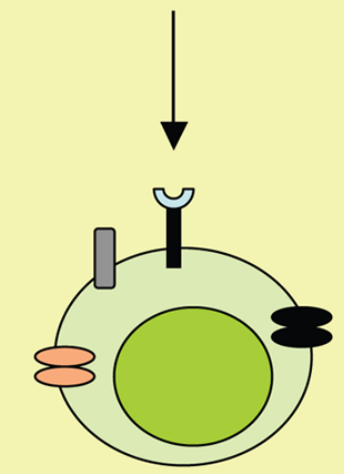

Naïve CD4 ${ }^{+} T$ cell
CRACM1+

CRACM2+++

CRACM3+

STIM1++

STIM2?

CRACM1+

CRACM2+++

CRACM3+

STIM1++

STIM2-

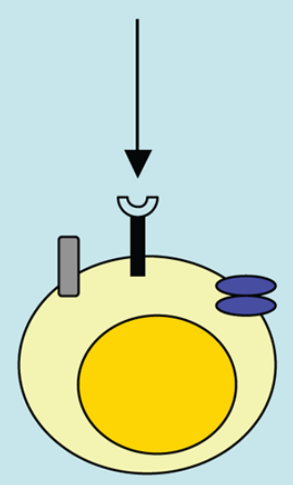

CRACM1?

CRACM2+

CRACM3?

STIM1++

STIM2+

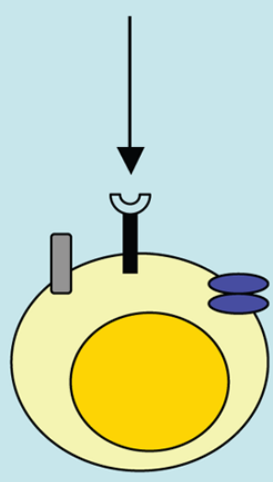

CRACM1++++

CRACM2++

CRACM3+++

STIM1+++

STIM2?

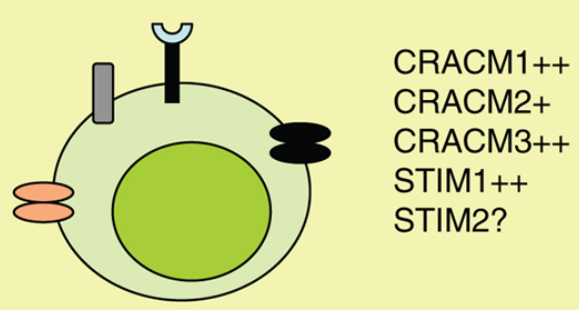

Activated $\mathrm{CD} 4^{+} \mathrm{T}$ cell

Figure 2.

Hypothetical model of the various modes of $\mathrm{Ca}^{2+}$ influx in developing, mature and activated $\mathrm{T}$ lymphocytes. Top (yellow shaded region), unknown chief source of $\mathrm{Ca}^{2+}$ influx; bottom (blue shaded region), SOCE is the main mode of $\mathrm{Ca}^{2+}$ influx;,+++ and +++ , reported changes (increases) in the expression of CRACM and STIM mRNA; ?, untested and unknown; -, undetectable; orange ovals, store-independent channels; black ovals, store-dependent channels. TCR, T cell antigen receptor; DP, double-positive. 
Table 1

Routes of cytosolic $\mathrm{Ca}^{2+}$ modulation in lymphocytes

\begin{tabular}{|c|c|c|c|}
\hline Route & Activation & Physiological outcome & Reference \\
\hline \multicolumn{4}{|l|}{ Pumps } \\
\hline SERCA & ATP & Pumps $\mathrm{Ca}^{2+}$ from cytosol to ER & 74 \\
\hline PMCA & ATP & $\begin{array}{l}\text { Prevents cytosolic } \mathrm{Ca}^{2+} \text { accumulation } \\
\text { and contributes to } \mathrm{Ca}^{2+} \text { signaling } \\
\text { dynamics }\end{array}$ & 75,76 \\
\hline \multicolumn{4}{|l|}{ Intracellular $\mathrm{Ca}^{2+}$ channels } \\
\hline $\operatorname{Ins}(1,4,5) \mathrm{P}_{3} \mathrm{R}, \mathrm{ER}$ & $\operatorname{Ins}(1,4,5) \mathrm{P}_{3}$ & Transient increase in cytosolic $\mathrm{Ca}^{2+}$ & 77 \\
\hline RyR & $\mathrm{Ca}^{2+}$, cADPR, L-type $\mathrm{Ca}^{2+}$ channels & Transient increase in cytosolic $\mathrm{Ca}^{2+}$ & 78,79 \\
\hline \multicolumn{4}{|l|}{$\mathrm{Ca}^{2+}$-selective store-operated channels } \\
\hline CRAC & Store-operated & Sustained increase in cytosolic $\mathrm{Ca}^{2+}$ & $4-6$ \\
\hline \multicolumn{4}{|c|}{ Nonselective (receptor- or store-operated) channels } \\
\hline TRPC & Diacylglycerol or store-operated? & Sustained increase in cytosolic $\mathrm{Ca}^{2+}$ & $7-9$ \\
\hline \multicolumn{4}{|l|}{ Ion exchangers } \\
\hline \multirow[t]{2}{*}{ Dual-mode sodium-calcium exchanger } & $\begin{array}{l}\text { Forward mode: high cytosolic } \mathrm{Ca}^{2+} \\
\text { concentrations }\end{array}$ & $\begin{array}{l}\text { Prevents accumulation of } \mathrm{Ca}^{2+} \text { in the } \\
\text { cytosol }\end{array}$ & 80,81 \\
\hline & $\begin{array}{l}\text { Reverse mode: high cytosolic } \mathrm{Na}^{+} \\
\text {concentrations }\end{array}$ & $\begin{array}{l}\text { Extrudes } \mathrm{Na}^{+} \text {and contributes to increase } \\
\text { in cytosolic } \mathrm{Ca}^{2+}\end{array}$ & 76,81 \\
\hline \multicolumn{4}{|l|}{ Mitochondrial $\mathrm{Ca}^{2+}$ buffering } \\
\hline $\begin{array}{l}\mathrm{Ca}^{2+} \text {-uptake channel: mitochondrial } \mathrm{Ca}^{2+} \\
\text { uniporter }\end{array}$ & High cytosolic $\mathrm{Ca}^{2+}$ concentrations & Buffers sub-plasmalemmal $\mathrm{Ca}^{2+}$ & 82,83 \\
\hline $\begin{array}{l}\mathrm{Ca}^{2+} \text {-extrusion channel: sodium-calcium } \\
\text { exchanger }\end{array}$ & High mitochondrial $\mathrm{Ca}^{2+}$ concentrations & $\begin{array}{l}\text { Buffers sub-plasmalemmal } \mathrm{Ca}^{2+} \text {, } \\
\text { facilitates ER refilling }\end{array}$ & 82,83 \\
\hline \multicolumn{4}{|l|}{ Indirect modulators of cytosolic $\mathrm{Ca}^{2+}$} \\
\hline TRPM4 and TRPM5 $\left(\mathrm{Na}^{+}\right.$channels $)$ & Membrane depolarization-activated & $\begin{array}{l}\text { Inhibits the driving force for CRAC- } \\
\text { mediated } \mathrm{Ca}^{2+} \text { influx }\end{array}$ & 52,54 \\
\hline Kv1.3 ( $\mathrm{K}^{+}$channel $)$ & Membrane depolarization-activated & $\begin{array}{l}\text { Potentiates the driving force for CRAC- } \\
\text { mediated } \mathrm{Ca}^{2+} \text { influx }\end{array}$ & 84 \\
\hline KCa3.1 ( $\mathrm{K}^{+}$channel $)$ & Calcium-activated & $\begin{array}{l}\text { Potentiates the driving force for CRAC- } \\
\text { mediated } \mathrm{Ca}^{2+} \text { influx }\end{array}$ & 84 \\
\hline \multicolumn{4}{|l|}{ Non-store-operated $\mathrm{Ca}^{2+}$ influx } \\
\hline Purinergic $\mathrm{P} 2$ receptors & Nucleotides & Nonselective cation influx & 85 \\
\hline TRPV6 (CaT1) & $\begin{array}{l}\text { Constitutively active; inhibited by } \\
\text { cytosolic increase in } \mathrm{Ca}^{2+}\end{array}$ & Selective $\mathrm{Ca}^{2+}$ influx & 1,86 \\
\hline TRPM2 (LTRPC2) & Pyrimidine nucleotides, ADPR and NAD & Nonselective cation influx & 87,88 \\
\hline TRPM7 (MIC or LTRPC7) & Intracellular $\mathrm{Mg}^{2+}$ concentrations & Nonselective cation influx & 89,90 \\
\hline ARC channel & Phosphorylation & Selective $\mathrm{Ca}^{2+}$ influx & 91 \\
\hline Ins $(1,4,5) \mathrm{P}_{3} \mathrm{R}, \mathrm{PM}$ (controversial) & $\operatorname{Ins}(1,4,5) \mathrm{P}_{3}$ & Unknown & 92 \\
\hline Cav (controversial) & Unclear in lymphocytes & $\begin{array}{l}\text { Contributes to increases in cytosolic } \\
\mathrm{Ca}^{2+} \text { and NFAT translocation }\end{array}$ & 71,72 \\
\hline
\end{tabular}

$\mathrm{CaT1}, \mathrm{Ca}^{2+}$ transport protein; ADPR, adenosine 5 ' diphosphoribose; NAD, nicotinamide adenine dinucleotide; LTRPC, long transient receptor potential channel; MIC, $\mathrm{Mg}^{2+}$ inhibited cation channel; PM, plasma membrane. 